\title{
Fusarium root rot of Asclepias curassavica: first report in Argentina
}

\author{
M. E. Petrone ${ }^{\mathrm{A}}$, M. C. Rivera ${ }^{\mathrm{A}, \mathrm{B}}$ and E. R. Wright ${ }^{\mathrm{A}}$ \\ AFaculty of Agronomy, University of Buenos Aires, Av. San Martín 4453 (1419), Ciudad de Buenos Aires, \\ Argentina. \\ ${ }^{\mathrm{B}}$ Corresponding author. Email: mrivera@agro.uba.ar
}

\begin{abstract}
Root rot caused by Fusarium oxysporum is reported for the first time on Asclepias curassavica in Buenos Aires. It appears to be the first report of the isolation and description of the causal agent of this disease on this host.
\end{abstract}

Asclepias curassavica (Asclepiadaceae) is an American evergreen sub-shrub, usually called Spanish flag in Argentina, because of its terminal and axial clusters of yellow and red flowers (Dimitri 1972). The species is also called bloodflower milkweed due to its milky sap. It blooms continuously

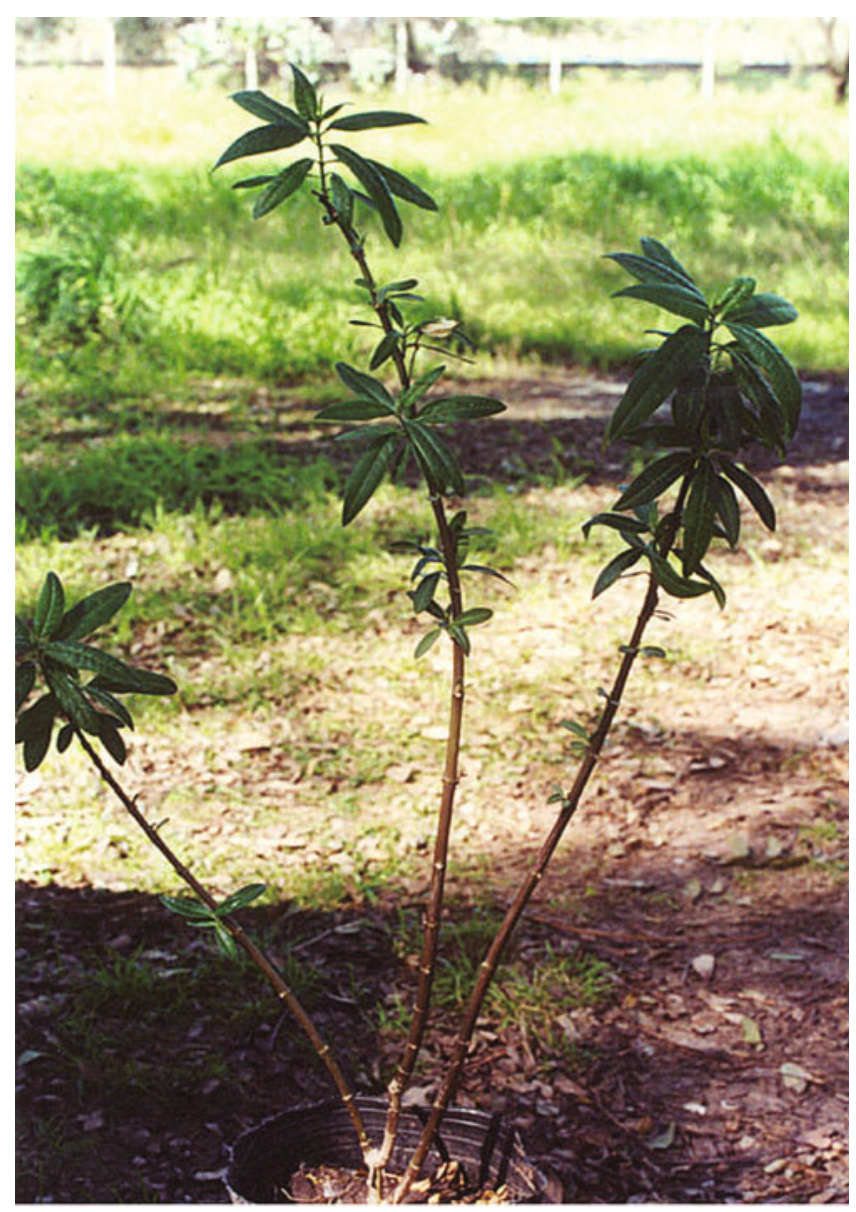

Fig. 1. Defoliation of a potted plant of Asclepias curassavica caused by Fusarium oxysporum. from spring until autumn and attracts Monarch butterflies. In September 2001, sudden wilt symptoms were observed in an experimental greenhouse located in Escobar (Buenos Aires, Argentina). The plants showed chlorosis and intense defoliation (Fig. 1) associated with root rot (Figs 2 and 3). Disease incidence was $30 \%$ from a total of 200 Spanish flag plants cultivated in the greenhouse. Identical symptoms were observed in November 2006 on plants cultivated in family gardens in Buenos Aires city.

Fusarium oxysporum (Booth 1971; Nelson et al. 1983) was consistently isolated from surface disinfected diseased roots after dipping into $70 \%$ ethanol for $1 \mathrm{~min}$ and $2 \% \mathrm{NaOCl}$ for $1 \mathrm{~min}$ and plating on potato dextrose agar (PDA). The fungus was characterised on the basis of conidial shape, size, septation and culture morphology. It grew rapidly on PDA, showing a purple undersurface. Abundant single-celled, oval microconidia were formed. Falcate macroconida were mostly 3 -septate $(37.0 \times 3.8 \mu \mathrm{m})$ and formed in sporodochia. The isolate produced single chlamydospores.

Pathogenicity tests were conducted by watering potted plants with a suspension adjusted to $1.2 \times 10^{6}$ conidia $/ \mathrm{mL}$ of sterilised distilled water. Control plants were irrigated with sterilised distilled water. Each plant was irrigated with a mean volume

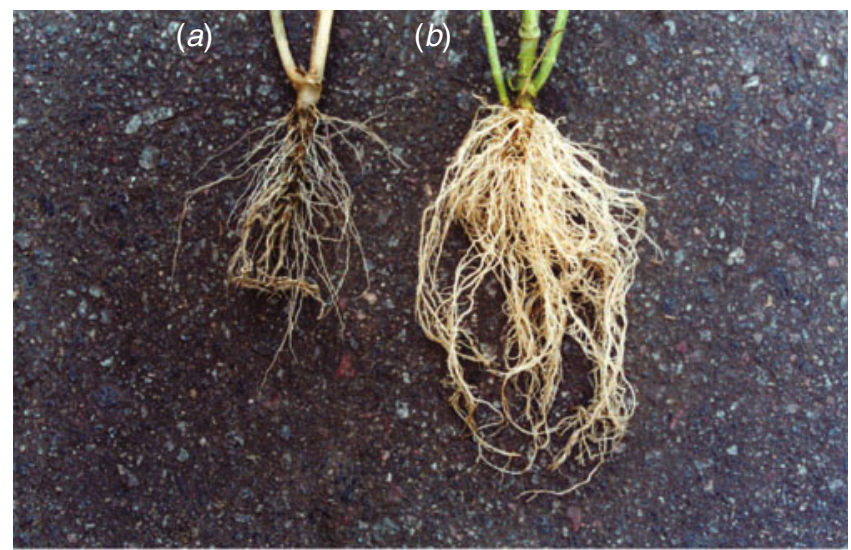

Fig. 2. (a) Roots of Asclepias curassavica infected by Fusarium oxysporum and (b) roots of healthy Asclepias curassavica (control plant). 


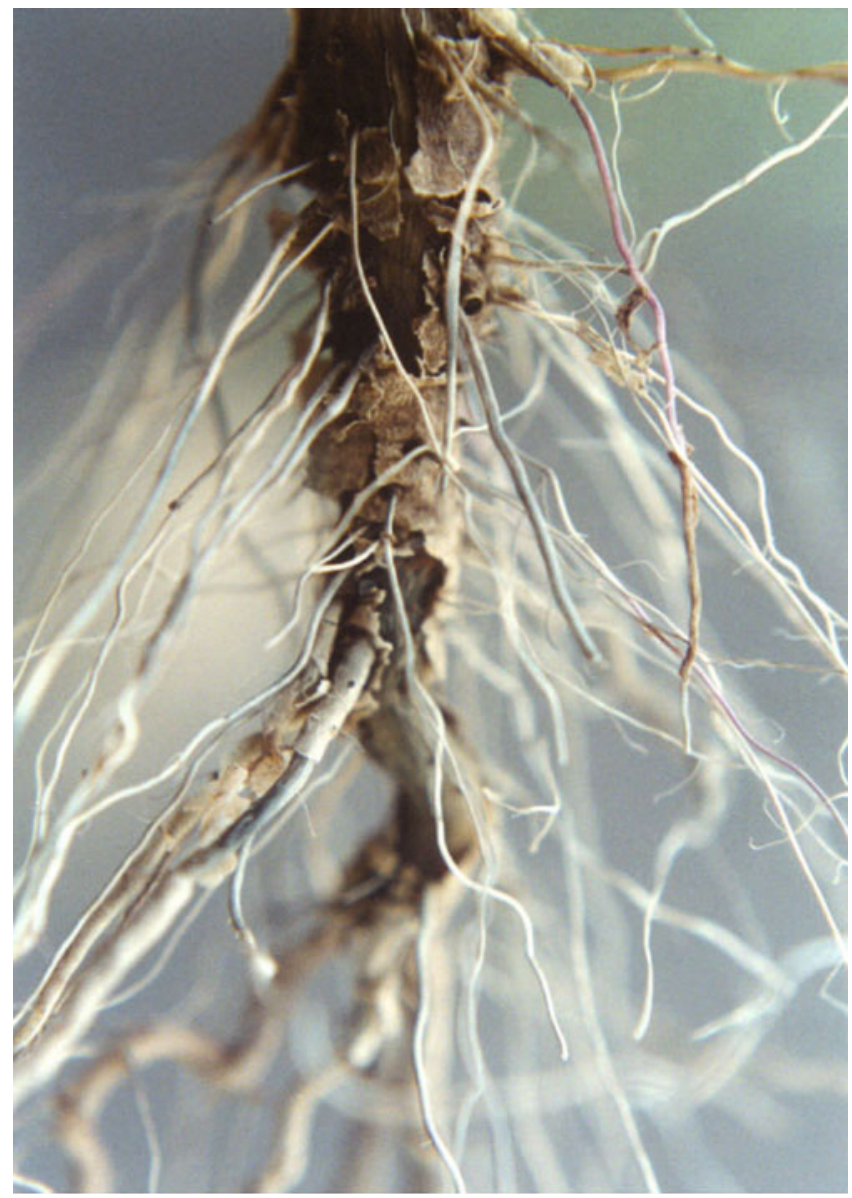

Fig. 3. Detail of damage caused by Fusarium oxysporum on roots of Asclepias curassavica. of $6.2 \mathrm{~mL}$, enclosed in a polyethylene bag and incubated at $22-24^{\circ} \mathrm{C}$ with a $12-\mathrm{h}$ photoperiod for 5 days. The bags were then removed.

Aerial symptoms became evident 38 days from inoculation and all the inoculated plants wilted within 48 days due to root rot, showing epinasty, intense loss of turgidity, leaf roll down and premature leaf drop. Control plants remained healthy. The fungus was reisolated from the diseased plants. Fusarium oxysporum is a cosmopolitan fungus that has been reported on many crops, including ornamentals. This is the first report of Fusarium wilt of $A$. curassavica in Argentina. So far as we know, no records have been published elsewhere. A culture of the pathogen has been lodged in the Culture Collection of the Department of Plant Pathology, Faculty of Agronomy, University of Buenos Aires. A survey to track the dispersal of the disease is ongoing.

\section{Acknowledgements}

This work was supported by grant UBACYT G085 from the University of Buenos Aires.

\section{References}

Booth C (1971) 'The Genus Fusarium' (Commonwealth Mycological Institute: Kew, UK)

Dimitri MJ (1972) 'Enciclopedia Argentina de Agricultura y Jardinería. Vol. I.' (Argentine Enciclopedia of Agriculture and Gardening; in Spanish) (Acme: Buenos Aires)

Nelson PE, Toussoun TA, Marasas WFO (1983) 'Fusarium species. An illustrated manual for identification.' (The Pennsylvania State University Press: University Park, PA)

Manuscript received 16 February 2007, accepted 19 March 2007 